\title{
AGulX nanoparticles as a promising platform for image-guided radiation therapy
}

\author{
Alexandre Detappe ${ }^{1,2^{*}}$, Sijumon Kunjachan ${ }^{1}$, Joerg Rottmann ${ }^{1}$, James Robar ${ }^{3}$, Panagiotis Tsiamas ${ }^{1}$, \\ Houari Korideck ${ }^{1}$, Olivier Tillement ${ }^{2}$ and Ross Berbeco ${ }^{1 *}$
}

*Correspondence:

Alex_Detappe@DFCl.Harvard.

edu; RBerbeco@LROC.

Harvard.edu

${ }^{1}$ Radiation Oncology Department, Dana-Farber Cancer Institute, Brigham and Women's Hospital, Harvard Medical School, Boston, MA 02215, USA Full list of author information is available at the end of the article

\begin{abstract}
AGuIX are gadolinium-based nanoparticles developed mainly for imaging due to their MR contrast properties. They also have a potential role in radiation therapy as a radiosensitizer. We used MRI to quantify the uptake of AGuIX in pancreatic cancer cells, and TEM for intracellular localization. We measured the radiosensitization of a pancreatic cancer cell line in a low-energy (220 kVp) beam, a standard $6 \mathrm{MV}$ beam (STD) and a flattening filter free $6 \mathrm{MV}$ beam (FFF). We demonstrated that the presence of nanoparticles significantly decreases cell survival when combined with an X-ray beam with a large proportion of low-energy photons (close to the k-edge of the nanoparticles). The concentration of nanoparticles in the cell achieves its highest level after $15 \mathrm{~min}$ and then reaches a plateau. The accumulated nanoparticles are mainly localized in the cytoplasm, inside vesicles. We found that the 6 MV FFF beams offer the best trade-off between penetration depth and proportion of low-energy photons. At $10 \mathrm{~cm}$ depth, we measured a $\mathrm{DEF}_{20} \%$ of $1.30 \pm 0.47$ for the $6 \mathrm{MV}$ FFF beam, compared to $1.23 \pm 0.26$ for the 6 MV STD beam. Additional measurements with un-incubated nanoparticles provide evidence that chemical processes might also be contributing to the dose enhancement effect.
\end{abstract}

Keywords: Nanomedicine, MRI, Gadolinium, Dose enhancement, Flattening filter free

\section{Background}

Nanoparticles made from high- $\mathrm{Z}$ materials are promising agents to increase radiosensitivity of cancer cells during the application of radiation therapy. Hainfeld et al. (2004, 2008) demonstrated therapeutic enhancement with gold nanoparticles (GNP) in a 250 $k V p$ X-ray beam. The dose-enhancing effect was attributed to the photoelectric effect and the increased generation of Auger electrons (Pradhan et al. 2009; Jelveh and Chithrani 2011; Dorsey et al. 2013; Kumar et al. 2013). Further studies have confirmed the dose-enhancing effect of GNP in $6 \mathrm{MV}$ X-ray beams, an energy range that is typically used for clinical radiation therapy (Detappe et al. 2013; Berbeco et al. 2011; Cho 2005; Jones et al. 2010; Lin et al. 2014; Robar et al. 2002; McMahon et al. 2008; Ngwa et al. 2014).

However, even though gold nanoparticles may be efficient radiosensitizers, it remains difficult to measure their exact concentration within the tumor with current clinically available imaging methods. To address this issue, multimodal nanoparticles have been

(C) 2015 Detappe et al. This article is distributed under the terms of the Creative Commons Attribution 4.0 International License (http://creativecommons.org/licenses/by/4.0/), which permits unrestricted use, distribution, and reproduction in any medium, provided you give appropriate credit to the original author(s) and the source, provide a link to the Creative Commons license, and indicate if changes were made. 
proposed that combine both therapeutic and diagnostic functionality. Mignot et al. 2013 developed a gadolinium-based nanoparticle, AGuIX, which is a non-toxic magnetic resonance contrast agent and sufficiently small (sub-5 $\mathrm{nm}$ diameter) to allow for renal clearance (Le Duc et al. 2014). With an atomic number of $Z=64$, gadolinium is a high-Z material and therefore also contributes substantial radiation dose enhancement. (Sancey et al. 2014).

Previous assessment of AGuIX nanoparticles has mostly focused on their imaging properties (Di Corato et al. 2013; Le Duc et al. 2011; Bianchi et al. 2014a, b; Paul et al. 2014). In vitro experiments have included different cell lines and preclinical irradiation beams (microbeam radiation therapy, low-energy X-ray). Researchers have shown early evidence of radiosensitization (Bianchi et al. 2013; Aspord et al. 2013; Mowat et al. 2011; Porcel et al. 2014; Stefančíková et al. 2014; Luchette et al. 2014). In addition, in vivo experiments with intravenous or intra-tumoral injection for subcutaneous and orthotopic lesions have been performed in preclinical radiation beams (Le Duc et al. 2011; Bianchi et al. 2014a).

The aim of the current study is to characterize the uptake of the AGuIX nanoparticles in pancreatic cancer cells by magnetic resonance imaging (MRI), and investigate the radiation dose enhancement effect attributable to AGuIX when irradiating the cells with a clinical linear accelerator at $6 \mathrm{MV}$. This represents the first step towards demonstrating an in vivo effect for pancreatic cancer. The AGuIX platform is particularly relevant for pancreatic cancer due to the poor prognosis, proximity of organs at risk, and targeting difficulty for this disease in radiation therapy. AGuIX offers a solution that is highly compatible with the current trend in radiation oncology towards MRI-based patient simulation and MRI-Linac treatment devices (Raaymakers et al. 2011; Keall et al. 2014). There may be a strong future for AGuIX in future MRI-guided radiation therapy for pancreatic cancer.

\section{Methods}

\section{Cell culture}

Panc1 cells were cultured in Dulbecco's Modified Eagle Medium (DMEM), supplemented with $10 \%$ fetal bovine serum (FBS) (Sigma, USA), 1 \% Penicillin Streptomycin Glutamine (Invitrogen, USA) and were stored in a humidified incubator at $37^{\circ} \mathrm{C}$ and $5 \%$ $\mathrm{CO}_{2}$.

\section{AGulX nanoparticles (Nano-H Inc., France)}

The nanoparticles are composed of a polysiloxane shell surrounded by DOTA (1,4,7,10-tetra-azacyclododecane-1-glutaric anhydride-4,7,10-triacetic acid) covalently bound to the inorganic matrix and Gadolinium (Fig. 1a). The size of each nanoparticle was measured by dynamic light scattering (DLS) and is $5 \pm 0.1 \mathrm{~nm}$ (Fig. 1d) with a mass of $10 \pm 1 \mathrm{kDa}$. More detailed information on the production process of the nanoparticles may be found in the references (Detappe et al. 2013).

\section{AGuIX uptake analysis with MRI and ICP-MS}

The concentration of the nanoparticles inside the cells was analyzed with a Bruker Biospin 7T Magnetic Resonance Imaging (MRI) scanner. First, a calibration curve without 


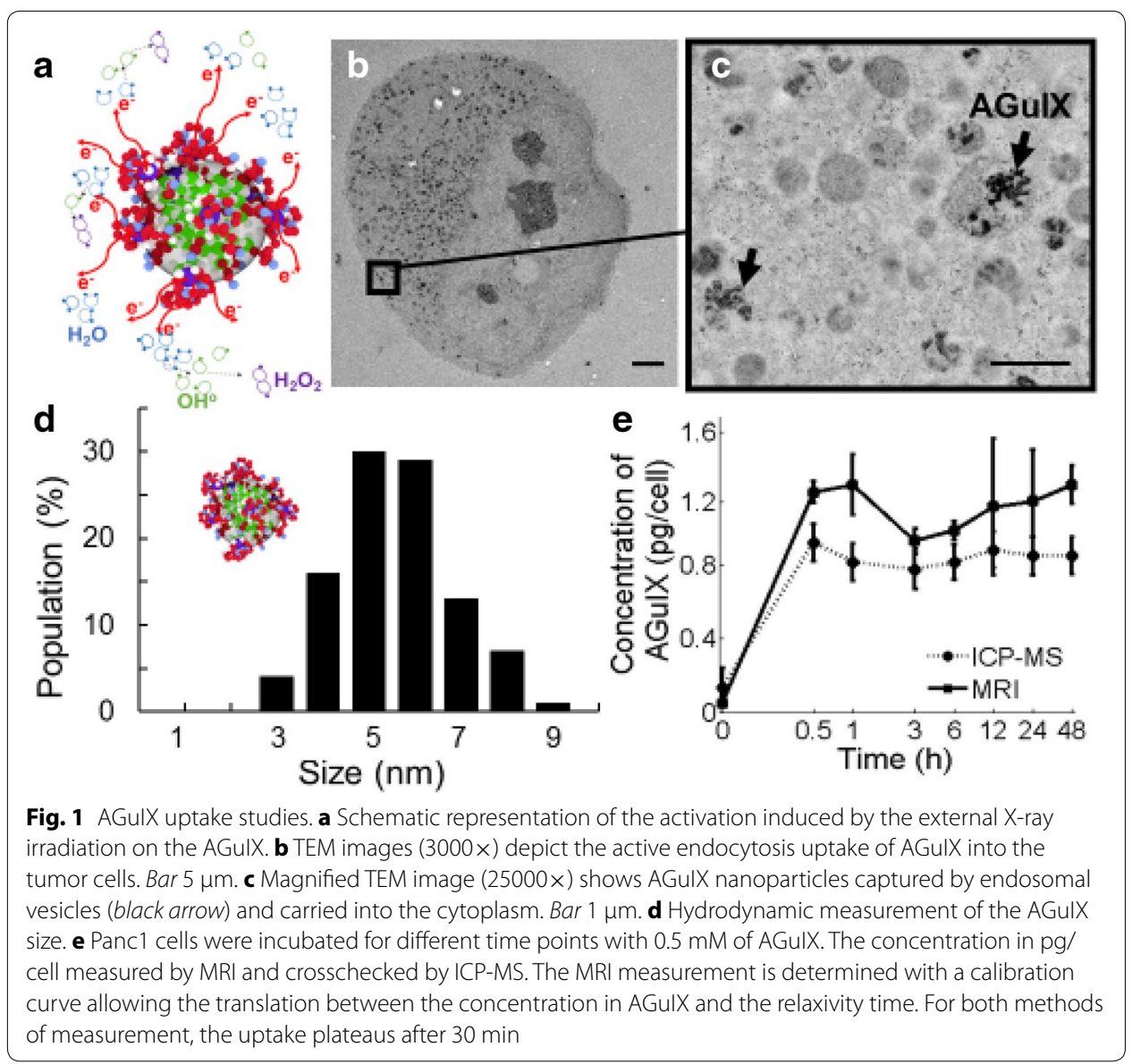

cells was acquired for various concentrations of nanoparticles in the cell culture solution. The concentration of AGuIX particles used for the experiment is given in gadolinium equivalent species and chosen based on published literature (Rima et al. 2013). Cells were incubated with $0.5 \mathrm{mM}(0.5 \mathrm{mg} / \mathrm{L})$ of AGuIX at $37^{\circ} \mathrm{C}$ and $5 \% \mathrm{CO}_{2}$ for $30 \mathrm{~min}$, $1 \mathrm{~h}, 3 \mathrm{~h}, 6 \mathrm{~h}, 24 \mathrm{~h}$ and $48 \mathrm{~h}$. After incubation, the cells were washed and trypsinized to remove any excess nanoparticles in the solution before scanning. All MRI scans featured a RARE-T1 map imaging-sequence with $2 \mathrm{~mm}$ slice thickness, repetition time of $10 \mathrm{~ms}$, echo time of $21.4 \mathrm{~ms}$, echo train length of 4 , flip angle of $180^{\circ}$, and matrix size $256 \times 128$ pixels. Each measurement was performed in triplicate.

Inductively coupled plasma mass spectrometry (ICP-MS) was used to validate the MRI results. For this procedure, the cells were dissolved in a radio-immuno precipitation RIPA buffer and then suspended in water until analysis. ICP-MS is used to determine the exact quantity of Gadolinium. As with the MRI measurements, incubation times were $30 \mathrm{~min}, 1 \mathrm{~h}, 3 \mathrm{~h}, 6 \mathrm{~h}, 24 \mathrm{~h}$ and $48 \mathrm{~h}$. Each time point was measured in triplicate.

\section{Localization of AGulX within Panc1 cells}

Transmission electronic microscopy (TEM) was performed to investigate the local nanoparticle distribution within the cells. A concentration of $0.5 \mathrm{mM}$ of AGuIX was 
incubated for $1 \mathrm{~h}$ with Panc1 cells, followed by washing out residual nanoparticles and staining with $4 \%$ formaldehyde and $1 \%$ glutaraldehyde in $0.1 \mathrm{M} \mathrm{Pb}$ for imaging.

\section{Irradiation and setup}

We investigated cell response to low-energy and high-energy photon irradiation for a dose range of 2-10 Gy. For low-energy experiments, we used a Small Animal Radiation Research Platform (SARRP) operated at $220 \mathrm{kVp}(0.15 \mathrm{~mm} \mathrm{Cu}$ filter) and a source to cell distance of $35 \mathrm{~cm}$. For high-energy irradiations, we used a clinical linear accelerator (TrueBeam, Varian Inc, USA) operated at $6 \mathrm{MV}$ with and without a flattening filter in the beam line. Using a flattening filter is the current standard (STD) in radiation therapy while the use of flattening filter free beams (FFF) is still relatively novel to clinical application. Cells were placed on $5 \mathrm{~cm}$ of water equivalent material and another $10 \mathrm{~cm}$ on top to allow for full scattering and back scattering conditions. The source to cell distance was $100 \mathrm{~cm}$, field size $10 \times 10 \mathrm{~cm}^{2}$ and dose rate $400 \mathrm{cGy} / \mathrm{min}$ for both STD and FFF deliveries.

\section{Clonogenic assay}

Panc1 cells were incubated in DMEM with $0.5 \mathrm{mM}$ of AGuIX following the specifications below, and then irradiated. After irradiations, the cells were incubated for another $4 \mathrm{~h}$; afterwards they were washed with PBS, trypsinized and counted. The cells were replated in $10 \mathrm{~cm}$ dishes at 300 cells per plate and allowed to grow for 10 days, before staining with a $1 \%$ crystal violet and $10 \%$ ethanol dye solution. The platting efficiency was $67 \pm 7 \%$. The plates were digitally scanned and automatically counted with software developed in our group. Measurements were performed in triplicate.

For the $6 \mathrm{MV}$ irradiations, the cells were incubated $1 \mathrm{~h}$ and the medium unwashed. For the low-energy photon experiments, 4 different configurations were investigated:

A. Irradiation without any nanoparticles.

B. Cells were not incubated with nanoparticles. Nanoparticles were placed in the media just prior the irradiation. We called this configuration $+\mathrm{IR} /$-incubation.

C. Cells were incubated with the nanoparticles and the media was changed just prior the irradiation. We called this +IR/+washing.

D. Cells were incubated with the nanoparticles and were irradiated. We called this $+\mathrm{IR} /$ - washing.

The (B) experiment (+IR/-incubation) is a test of the hypothesis that a dose enhancement effect can be caused by nanoparticles located outside the cell. A positive result supports the presence of some long-range effects beyond just photoelectric and Auger processes.

\section{Data analysis}

We quantified the effect of the nanoparticles utilizing three methods commonly found in the literature (Sancey et al. 2014; Jain et al. 2011; Chithrani et al. 2010; Roeske et al. 2007). The Dose Enhancement Factor (DEF) is the ratio of the area between the survival curves with and without nanoparticles. The $\mathrm{DEF}_{20} \%$ is the ratio of doses at $20 \%$ survival 
for irradiation without nanoparticles versus with nanoparticles. The sensitivity enhancement ratio at $4 \mathrm{~Gy}\left(\mathrm{SER}_{4 \mathrm{~Gy}}\right)$ is the ratio of survival fractions at $4 \mathrm{~Gy}$ for irradiation without and with nanoparticles.

To characterize the radiation response of the Panc1 cells with and without AGuIX, we employed the classical linear quadratic model (LQM):

$$
S(D)=\exp \left(-\alpha D-\beta D^{2}\right)
$$

Here, $S$ is the cell survival fraction, $D$ the irradiation dose and $\alpha$ and $\beta$ are parameters representing direct lethal and sub-lethal damage, respectively. Statistical significance of cell survival changes with the application of nanoparticles is calculated using a KruskalWallis test.

\section{Results and discussion}

\section{Uptake measurement}

Results from both MRI and ICP-MS uptake analyses are shown in Fig. 1. Both methods give consistent results and show that AGuIX uptake saturates at about 1.25 pg per cell after 30 min incubation time for $0.5 \mathrm{mM}$ of AGuIX incubated.

TEM imaging (Fig. 1b, c) reveals that after $1 \mathrm{~h}$ of incubation, the nanoparticles are predominantly localized in vacuoles in the cytoplasm. This result is in agreement with the previously published studies that applied AGuIX to other cell lines (Stefančíková et al. 2014; Rima et al. 2013).

MRI and ICP-MS results both show a constant level of nanoparticles inside the cells after 30 min of incubation. The MRI measurement is systematically larger than the ICPMS measurement. This is because the T1 signal is sensitive to the size of nanoparticles, which decrease during hydrolysis (which occurs due to the low AGuIX concentration) (Le Duc et al. 2014).

\section{Activation of the nanoparticles}

For the highest probability of a photoelectric interaction with the K-shell of Gadolinium, the incident photon should have an energy just above $50 \mathrm{keV}$. Figure 2a shows a comparison of the low-energy photon spectra for the beams used in this study. Spectra are generated using EGSnrc Monte Carlo code (Tsiamas et al. 2011, 2014).

From these distributions, it is clear that $220 \mathrm{kVp}$ is expected to have the highest dose enhancement. However, it is not clinically feasible to use low-energy photons to treat the majority of patients (especially pancreatic cancer patient) due to the poor penetration depth and skin-sparing properties. Figure $2 \mathrm{~b}$ shows a comparison of the percentage depth dose (PDD) for the radiation beams used in this study. The best trade-off between penetration depth and proportion of low-energy photons exists for the 6 MV FFF beam. Further modifications of the $6 \mathrm{MV}$ beam, including the use of a low-Z target, (Parsons et al. 2014) may also improve the dose enhancement while preserving the deep penetration properties. 

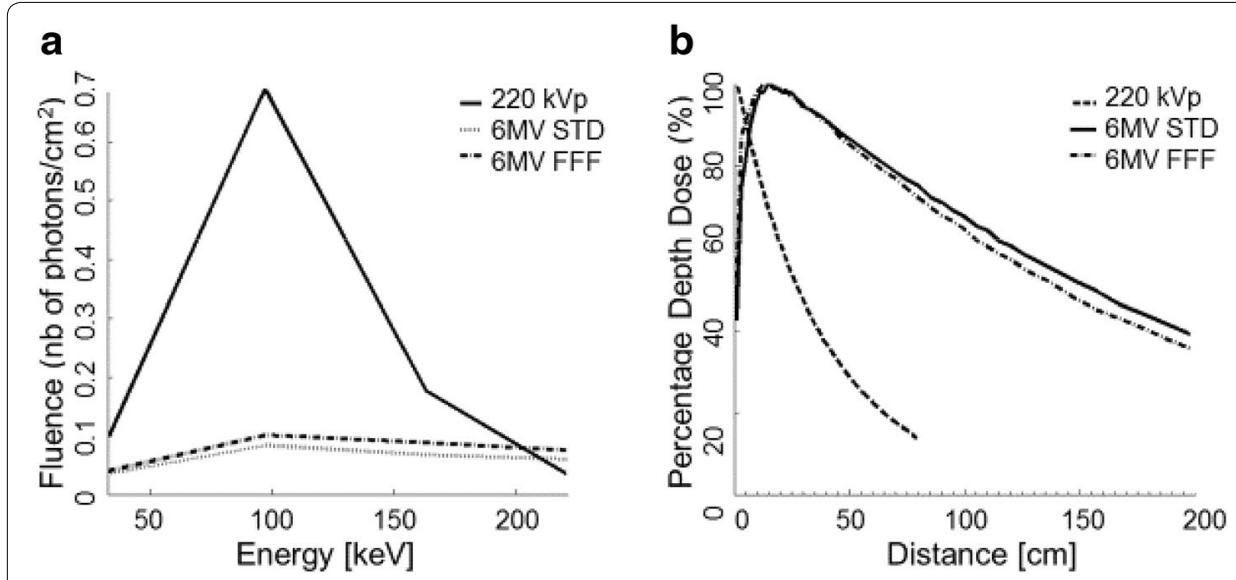

Fig. 2 Representation of the difference between the preclinical beam (SARRP) and the clinical beam. a The 3 different spectra (220 kVp, 6 MV FFF, and 6 MV STD) were represented near the k-edge of the Gadolinium (50.2 kV). Calculation were performed with Monte Carlo simulation at $35 \mathrm{~cm}$ source-skin distance; $12 \mathrm{~mm}$ circular field size for the $220 \mathrm{kVp}$ machine, and at $90 \mathrm{~cm}$ source-skin distance; $10 \mathrm{~cm}$ depth; $10 \times 10 \mathrm{~cm}^{2}$ field size for the $6 \mathrm{MV}$ irradiations. $\mathbf{b}$ Percentage depth dose (PDD) for the 3 photon beams. The maximum dose for the $220 \mathrm{kVp}$ occurs at the surface while it is at approximately $1.5 \mathrm{~cm}$ for both $6 \mathrm{MV}$ beams

\section{Dose enhancement effects}

A significant radiosensitization effect was observed for all the clonogenic assays performed (Fig. 3). Results of the dose enhancement studies are summarized in Table 1. The dose enhancement effect appears to increase with the proportion of low-energy photons in the spectrum as expected (Detappe et al. 2013; Berbeco et al. 2011). For the high-energy (clinical) photon beams, cell killing is significantly increased by the removal of the flattening filter in the FFF beam, compared to the STD beam ( $p=0.014$, Wilcoxon). The SER SGy $_{\text {is }} 1.20 \pm 0.04$ for the FFF irradiation and $1.12 \pm 0.04$ for the STD. The $\mathrm{DEF}_{20 \%}$ is $1.30 \pm 0.05$ for the FFF and $1.23 \pm 0.03$ for the STD.

While the physical property of the incident radiation beams clearly provides a therapeutic advantage, there may be other factors contributing as well. Figure $1 \mathrm{~b}, \mathrm{c}$ shows the nanoparticles clustered inside the cytoplasm, away from the DNA. Radiosensitization was observed for this scenario as well as for non-incubated nanoparticles (located outside the cell) (Fig. 3d). McMahon et al. (2011) demonstrated the role of Auger electrons to create a local effect and the impact of nanoparticle clustering. This local effect increases the formation of reaction oxygen species (ROS), such as $\mathrm{OH}^{\circ}, \mathrm{H}_{2} \mathrm{O}_{2}$, or $\mathrm{HOCl}$. Some of these ROS have high chemical stabilities and a long-range action (few $\mathrm{mm}$ ) that may increase the cell death even if the nanoparticles are not localized in the cells. The results shown in Fig. $3 \mathrm{~d}$ are similar to those obtained by Porcel et al. (2014) for hadrontherapy. Thus, in addition to the physical properties, a biological or chemical effect should be explored to explain the measured radiosensitization. 
a

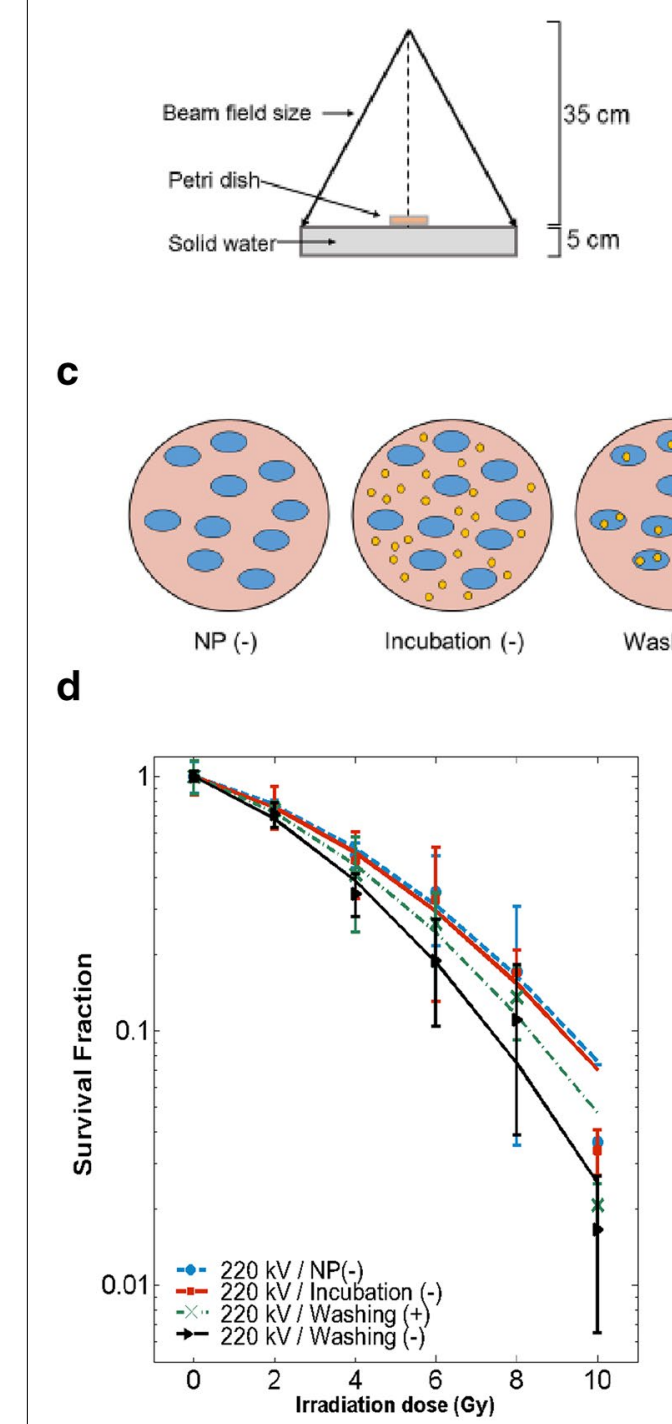

b

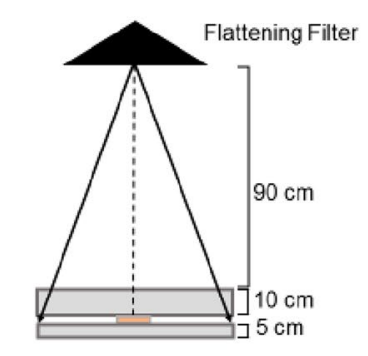

Fig. 3 Radiation dose enhancement studies. Clonogenic assays of Panc1 tumor cells post-AGulX incubation (1 h). a Schematic view of the irradiation setup for the preclinical beam (220 kVp) and $\mathbf{b}$ for the clinical beam (6 MV). The flattening filter is removed for the FFF irradiations. c Schematic representation of the clonogenic assay for the preclinical irradiations. Clinical irradiations were performed with the "washing (-)" situation. Blue circles represents the cells. Yellow circles represent the nanoparticles. $\mathbf{d}$ Preclinical irradiation setup (SARRP) was used to induce radiation enhancement effect in AGuIX using a $220 \mathrm{kVp}$ beam (left) and clinical irradiation setup (6 MV beam) was used to treat cells with (STD) and without (FFF) flattening filter (right). Linear quadratic models were fitted to experimental data

\section{Conclusion}

AGuIX nanoparticles create significant dose enhancement in Panc1 cell lines for lowand high-energy photon irradiation. Using a $6 \mathrm{MV}$ flattening filter free (FFF) beam improves dose enhancement compared to a standard 6 MV beam. Because of their contrast in MRI images, AGuIX have excellent potential as theranostic agents (Lux et al. 2011; Kunjachan et al. 2012). 
Table 1 Dose enhancement effect in terms of DEF, DEF $20 \%$ and $\mathrm{SER}_{4 \mathrm{~Gy}}$ for Panc1 cells incubated with $0.5 \mathrm{mM}$ AGuIX

\begin{tabular}{|c|c|c|c|c|c|}
\hline \multicolumn{6}{|l|}{ Irradiation } \\
\hline \multirow[t]{2}{*}{ Preparation } & \multicolumn{3}{|l|}{$220 \mathrm{kVp}$} & \multirow{2}{*}{$\begin{array}{l}6 \text { MV FFF } \\
\text { AGulX } 1 \mathrm{~h} \\
\text { incubation } \\
\text { unwashing }\end{array}$} & \multirow[t]{2}{*}{6 MV STD } \\
\hline & $\begin{array}{l}\text { AGulX no } \\
\text { incubation }\end{array}$ & $\begin{array}{l}\text { AGulX } 1 \mathrm{~h} \\
\text { incubation } \\
\text { washing }\end{array}$ & $\begin{array}{l}\text { AGulX } 1 \mathrm{~h} \\
\text { incubation } \\
\text { unwashing }\end{array}$ & & \\
\hline DEF & 1.09 & 1.17 & 1.46 & 1.23 & 1.19 \\
\hline DEF $20 \%$ & 1.01 & 1.1 & 1.31 & 1.3 & 1.23 \\
\hline Sensitivity (SER4Gy) & 1.05 & 1.19 & 1.41 & 1.2 & 1.12 \\
\hline$p$ value & 0.131 & 0.038 & $* * *$ & 0.009 & 0.011 \\
\hline
\end{tabular}

$p$ values were calculated using a Kruskal Wallis to test the effect of the nanoparticles with the control

*** $p<0.001$

\section{Authors' contributions}

$A D, J R$ and HK performed the irradiations studies. AD and SK performed the biological part of the study. JR and PT generated the simulation data. AD, SK and RB conceived the study, and participated in its design and coordination. OT provided the nanoparticles. All authors helped to draft the manuscript. All authors read and approved the final manuscript.

\section{Competing interests}

The authors declare that they have no competing interests.

\section{Author details}

${ }^{1}$ Radiation Oncology Department, Dana-Farber Cancer Institute, Brigham and Women's Hospital, Harvard Medical School, Boston, MA 02215, USA. ${ }^{2}$ Institut Lumière-Matière, Université Claude Bernard, 69000 Lyon, France. ${ }^{3}$ Department of Medical Physics, Nova Scotia Cancer Centre, Dalhousie University, Halifax, NS B3H 1V7, Canada.

Received: 26 March 2015 Accepted: 25 August 2015

Published online: 02 September 2015

\section{References}

Aspord C, Laurin D, Janier MF, Mandon CA, Thivolet C, Villiers C, Mowat P, Madec AM, Tillement O, Perriat P, et al. Paramagnetic nanoparticles to track and quantify in vivo immune human therapeutic cells. Nanoscale. 2013;5(23):11409-15.

Berbeco R, Ngwa W, Makrigiorgos M. Localized dose enhancement to tumor blood vessel endothelial cells via megavoltage X-rays and targeted gold nanoparticles: new potential for external beam radiotherapy. Int J Radiat Oncol Biol Phys. 2011:81(1):270-6.

Bianchi A, Dufort S, Lux F, Courtois A, Tillement O, Coll JL, Crémillieux Y. Quantitative biodistribution and pharmacokinetics of multimodal gadolinium-based nanoparticles for lungs using ultrashort TE MRI. MAGMA. 2014b;27(4):303-16.

Bianchi A, Dufort S, Lux F, Fortin PY, Tassali N, Tillement O, Coll JL, Crémillieux Y. Targeting and in vivo imaging of nonsmall-cell lung cancer using nebulized multimodal contrast agents. Proc Natl Acad Sci USA. 2014a;111(25):9247-52.

Bianchi A, Lux F, Tillement O, Crémillieux Y. Contrast enhanced lung MRI in mice using ultra-short echo time radial imaging and intratracheally administrated Gd-DOTA-based nanoparticles. Magn Reson Med. 2013;70(5):1419-26.

Chithrani DB, Jelveh S, Jalali F, van Prooijen M, Allen C, Bristow RG, Hill RP, Jaffray DA. Gold nanoparticles as radiation sensitizers in cancer therapy. Radiat Res. 2010;173(6):719-28.

Cho SH. Estimation of tumour dose enhancement due to gold nanoparticles during typical radiation treatments: a preliminary Monte Carlo study. Phys Med Biol. 2005;50(15):N163-73.

Di Corato R, Gazeau F, Le Visage C, Fayol D, Levitz P, Lux F, Letourneur D, Luciani N, Tillement O, Wilhelm C. High-resolution cellular MRI: gadolinium and iron oxide nanoparticles for in-depth dual-cell imaging of engineered tissue constructs. ACS Nano. 2013;7(9):7500-12.

Detappe A, Tsiamas P, Ngwa W, Zygmanski P, Makrigiorgos M, Berbeco R. The effect of flattening filter free delivery on endothelial dose enhancement with gold nanoparticles. Med Phys. 2013;40(3):031706.

Dorsey JF, Sun L, Joh DY, Witztum A, Kao GD, Alonso-Basanta M, Avery S, Hahn SM, Al Zaki A, Tsourkas A. Gold nanoparticles in radiation research: potential applications for imaging and radiosensitization. Transl Cancer Res. 2013;2(4):280-91.

Le Duc G, Miladi I, Alric C, Mowat P, Bräuer-Krisch E, Bouchet A, Khalil E, Billotey C, Janier M, Lux F, et al. Toward an imageguided microbeam radiation therapy using gadolinium-based nanoparticles. ACS Nano. 2011;5(12):9566-74.

Le Duc G, Roux S, Paruta-Tuarez A, Dufort S, Brauer E, Marais A, Truillet C, Sancey L, Perriat P, Lux F, et al. Advantages of gadolinium based ultrasmall nanoparticles vs molecular gadolinium chelates for radiotherapy guided by MRI for glioma treatment. Cancer Nanotechnol. 2014;5:4.

Hainfeld JF, Dilmanian FA, Slatkin DN, Smilowitz HM. Radiotherapy enhancement with gold nanoparticles. J Pharm Pharmacol. 2008;60(8):977-85. 
Hainfeld JF, Slatkin DN, Smilowitz H. The use of gold nanoparticles to enhance radiotherapy in mice. Phys Med Biol. 2004;49(18):N309-15.

Jain S, Coulter JA, Hounsell AR, Butterworth KT, McMahon SJ, Hyland WB, Muir MF, Dickson GR, Prise KM, Currell FJ, O'Sullivan JM, Hirst DG. Cell-specific radiosensitization by gold nanoparticles at megavoltage radiation energies. Int J Radiat Oncol Biol Phys. 2011;79:531-9.

Jelveh S, Chithrani DB. Gold nanostructures as a platform for combinational therapy in future cancer therapeutics. Cancers (Basel). 2011;3(1):1081-110.

Jones BL, Krishnan S, Cho SH. Estimation of microscopic dose enhancement factor around gold nanoparticles by Monte Carlo calculations. Med Phys. 2010;37(7):3809-16.

Keall PJ, Barton M, Crozier S. The Australian magnetic resonance imaging-linac program. Semin Radiat Oncol. 2014;24(3):203-6.

Kumar R, Korideck H, Ngwa W, Berbeco RI, Makrigiorgos GM, Sridhar S. Third generation gold nanoplatform optimized for radiation therapy. TransI Cancer Res. 2013;2(4). doi.10.3978/j.issn.2218-676X.2013.07.02.

Kunjachan S, Jayapaul J, Mertens ME, Storm G, Kiessling F, Lammers T. Theranostic systems and strategies for monitoring nanomedicine-mediated drug targeting. Curr Pharm Biotechnol. 2012;13(4):609-22.

Lin Y, McMahon SJ, Scarpelli M, Paganetti H, Schuemann J. Comparing gold nano-particle enhanced radiotherapy with protons, megavoltage photons and kilovoltage photons: a Monte Carlo simulation. Phys Med Biol. 2014;59(24):7675-89.

Luchette M, Korideck H, Makrigiorgos M, Tillement O, Berbeco R. Radiation dose enhancement of gadolinium-based AGulX nanoparticles on HeLa cells. Nanomedicine. 2014;10(8):1751-5.

Lux F, Mignot A, Mowat P, Louis C, Dufort S, Bernhard C, Denat F, Boschetti F, Brunet C, Antoine R, et al. Ultrasmall rigid particles as multimodal probes for medical applications. Angew Chem Int Ed Engl. 2011;50(51):12299-303.

McMahon SJ, Hyland WB, Muir MF, Coulter JA, Jain S, Butterworth KT, Schettino G, Dickson GR, Hounsell AR, O'Sullivan JM, et al. Biological consequences of nanoscale energy deposition near irradiated heavy atom nanoparticles. Sci Rep. 2011;1:18.

McMahon SJ, Mendenhall MH, Jain S, Currell F. Radiotherapy in the presence of contrast agents: a general figure of merit and its application to gold nanoparticles. Phys Med Biol. 2008;53:5635-51.

Mignot A, Truillet C, Lux F, Sancey L, Louis C, Denat F, Boschetti F, Bocher L, Gloter A, Stéphan O, et al. A top-down synthesis route to ultrasmall multifunctional Gd-based silica nanoparticles for theranostic applications. Chemistry. 2013;19(19):6122-36.

Mowat P, Mignot A, Rima W, Lux F, Tillement O, Roulin C, Dutreix M, Bechet D, Huger S, Humbert L, et al. In vitro radiosensitizing effects of ultrasmall gadolinium based particles on tumour cells. J Nanosci Nanotechnol. 2011;11(9):7833-9.

Ngwa W, Kumar R, Sridhar S, Korideck H, Zygmanski P, Cormack RA, Berbeco R, Makrigiorgos M. Targeted radiotherapy with gold nanoparticles: current status and future perspectives. Nanomed (Lond). 2014;9(7):1063-82.

Parsons D, Robar JL, Sawkey D. A Monte Carlo investigation of low-Z target image quality generated in a linear accelerator using Varian's VirtuaLinac. Med Phys. 2014;41(2):021719.

Paul G, Prado Y, Dia N, Rivière E, Laurent S, Roch M, Elst LV, Muller RN, Sancey L, Perriat P, et al. Mnll-containing coordination nanoparticles as highly efficient T1 contrast agents for magnetic resonance imaging. Chem Commun (Camb). 2014;50(51):6740-3.

Porcel E, Tillement O, Lux F, Mowat P, Usami N, Kobayashi K, Furusawa Y, Le Sech C, Li S, Lacombe S. Gadolinium-based nanoparticles to improve the hadrontherapy performances. Nanomedicine. 2014;10(8):1601-8.

Pradhan AK, Nahar SN, Montenegro M, Yu Y, Zhang HL, Sur C, Mrozik M, Pitzer RM. Resonant X-ray enhancement of the Auger effect in high-Z atoms, molecules, and nanoparticles: potential biomedical applications. J Phys Chem A. 2009;113(45):12356-63.

Raaymakers BW, de Boer JC, Knox C, Crijns SP, Smit K, Stam MK, van den Bosch MR, Kok JG, Lagendijk JJ. Integrated megavoltage portal imaging with a 1.5 T MRI linac. Phys Med Biol. 2011;56(19):207-14.

Rima W, Sancey L, Aloy MT, Armandy E, Alcantara GB, Epicier T, Malchère A, Joly-Pottuz L, Mowat P, Lux F, et al. Internalization pathways into cancer cells of gadolinium-based radiosensitizing nanoparticles. Biomaterials. 2013;34(1):181-95.

Robar JL, Riccio SA, Martin MA. Tumour dose enhancement using modified megavoltage photon beams and contrast media. Phys Med Biol. 2002;47:2433-49.

Roeske JC, Nunez L, Hoggarth M, Labay E, Weichselbaum RR. Characterization of the theoretical radiation dose enhancement from nanoparticles. Technol Cancer Res Treat. 2007;6(5):395-401.

Sancey L, Lux F, Kotb S, Roux S, Dufort S, Bianchi A, Crémillieux Y, Fries P, Coll JL, Rodriguez-Lafrasse C, et al. The use of theranostic gadolinium-based nanoprobes to improve radiotherapy efficacy. Br J Radiol. 2014;87(1041):20140134.

Stefančíková L, Porcel E, Eustache P, Li S, Salado D, Marco S, Guerquin-Kern JL, Réfrégiers M, Tillement O, Lux F, et al. Cell localisation of gadolinium-based nanoparticles and related radiosensitising efficacy in glioblastoma cells. Cancer Nanotechnol. 2014;5(1):6.

Tsiamas P, Sajo E, Cifter F, Theodorou K, Kappas C, Makrigiorgos M, Marcus K, Zygmanski P. Beam quality and dose perturbation of 6 MV flattening-filter-free linac. Phys Med. 2014;30(1):47-56.

Tsiamas P, Seco J, Han Z, Bhagwat M, Maddox J, Kappas C, Theodorou K, Makrigiorgos M, Marcus K, Zygmanski P. A modification of flattening filter free linac for IMRT. Med Phys. 2011;38(5):2342-5239. 